\title{
Predicting social and personal attraction in task groups
}

\author{
David Dryden Henningsen ${ }^{1}$, Mary Lynn Miller Henningsen², \\ and Paul Booth ${ }^{3}$
}

\begin{abstract}
Equity and market forces are examined for their influence on the formation of social and personal attraction in groups. It is hypothesized that perceptions of task and maintenance behaviors during group interactions influence individuals' perceptions of costs and rewards in groups which, in turn, drive assessments of social and personal attraction via either equity or market forces. Results indicate that equity forces are significantly linked with perceptions of social attraction and market forces significantly predict personal attraction. Theoretical implications are discussed regarding equity theory, social exchange theory, and relational framing theory.
\end{abstract}

Keywords: cohesiveness, group cohesion, group performance, personal attraction, social attraction

1. Professor, Dept of Communications, N Illinois University

2. Associae Professor, Dept of Communications, N Illinois University

3. Assistant Professor, Communication, DePaul University

Address for correspondence: Northern Illinois University, Department of Communication, DeKalb IL, 60115, USA.tm0dxh1@wpo.cso.niu.edu

Date of first (online) publication:

Groupwork Vol. 23(1), 2013, pp.73-93. DOI: 10.1921/1701230105 
Much research in groups focuses on how attraction to a group or to the groups' members influence productivity (Mullen \& Copper, 1994). Debate surrounds the effects of attraction, often identified as cohesiveness, on productivity. Different scholars have argued attraction to a group can be counter-productive (for example, Burnette, Pollack, $\&$ Forsyth, 2011; Janis, 1972, 1983; Janis \& Mann, 1977), can increase productivity (for example., Mullen \& Copper, 1994; Mach, Dolan, \& Tzafrir, 2010; Shin \& Song, 2011), or has little effect (for example, Keyton \& Springston, 1990).

In the present study, attraction members feel to a group or to the members of the group are examined as output rather than input variables. The concept of attraction to a group includes and incorporates within it the quality of the relationships a person has with the group and with the other group members. We explore what role perceptions of communication plays in the development of attraction to a group and its members. More specifically, in the present study we will explore two types of attraction within a group, namely personal and social attraction.

One distinction that has been made in the literature exploring attraction in groups is between personal attraction and social attraction (for example, Hogg \& Hains, 1998; Hogg \& Hardie, 1991; Hogg, Abrams, Otten, \& Hinkle, 2004). Personal attraction represents the positive regard one individual has for another. Social attraction, on the other hand, is depersonalized and depends on the extent to which individuals perceive themselves as matching the group prototype. Social attraction thus focuses not on a given member but on the group as an entity. Given these definitions, personal attraction relates to the liking of individuals within a group and social attraction better reflects liking of the group as a whole.

In the present study, the influence of perceptions of interaction on the development of both personal attraction and social attraction are examined. More specifically, in the present study we focus on perceptions of group members' behavior during group interactions and the role of those perceptions in the development of attraction. In particular, we examine how the perceived contributions individuals make to the group task and to group maintenance influence social and personal attraction. Two theoretical frameworks, grounded in equity and market forces, are considered. 


\section{Equity forces and social attraction}

Equity theory holds that individuals are motivated to pursue balanced relationships (Walster, Berscheid, \& Walster, 1973). This balance is predicated on an equity norm. The equity norm states that the ratio of benefits to costs for a person in a relationship should be roughly equal to that of his or her partner. Perceived violations of the equity norm arouse distress in individuals. Particularly, equity theory argues that people who receive more from a relationship than their partner (that is, over-benefited people) will feel guilty and those who receive less from the relationship than their partner (under-benefited people) will feel angry. In contrast, people in equitable relationships should not feel distress but should feel satisfied with the relationship.

Equity theory relies on a form of normative influence (Deutsch \& Gerard, 1955; Kaplan, 1989). Normative influence occurs when individuals desire to adhere to group or societal standards in order to avoid punishments (for example, estrangement from the group) or to gain rewards (for example, social approval by the group) associated with acceptance by the group. When an individual violates a norm, the group of which that individual is a member may sanction the individual, often in the form of alienation. Therefore, attraction to the group as a unit is strongly linked to the amount of normative force that can be exerted. The distress caused by violating equity norms is a response to societal pressure to form fair and equitable relationships (Walster et al, 1973). In a group, this pressure would occur when the group perceives some members are over- or under-benefitted.

Equity theory leads to the prediction that group members would best like groups when their own contributions neither exceed nor lag behind those of others in the group. We argue that contributions by other group members represent benefits to the individual while contributions by the individual him or herself represent a cost. Thus, contrasting self and other contributions provides a ratio of costs and benefits. Because we argue equity theory is normative in nature, we feel equity relates strongly to social attraction (for example, Hogg \& Hains, 1998). The perceived similarity of contributions by group members should reinforce the group prototype.

When contributions differ greatly within a group, however, the ability to define the group prototype should be diminished hurting

Groupwork Vol. 23(1), 2013, pp.73-93. DOI: 10.1921/1701230105 
social attraction. In such cases under-performing and over-performing group members may generate negative impressions due to threats to the groups' sense of unity.

Consider the example of a sports team. If one member of that team feels their contributions greatly exceed or greatly lag behind the performance of the other team members, that member should feel that they do not fit the group prototype. Thus, a team member who feels over-benefited (he or she does not contribute as much to the team as others) or under-benefited (he or she contributes more to the team than others) will feel less similar to the group prototype. In this way inequity threatens social attraction in groups. Thus, equity is posited to predict social attraction.

\section{The market forces and personal attraction}

Market forces explanations of attraction indicate individuals form evaluations based on the economic principles of costs and rewards. For instance, individuals can evaluate relationships based on the minimax principle (Forsyth, 2006). That is, individuals prefer relationships that maximize the rewards they receive and minimize the costs (for example, Moreland \& Levine, 1982; Thibault \& Kelley, 1959). In a group context, rewards are received when other group members make valuable contributions to the group. In contrast, costs are incurred to the extent that the group member must commit personal resources to group tasks and functions. Thus, an individual can evaluate group members by comparing their own contributions to those of the other group members.

Unlike equity forces, if an individual seeks to maximize rewards and minimize costs the individual should favor group members whose contributions to the group exceed those of the individual (they are rewarding). In contrast, group members who contribute less to the group than the individual should be viewed less favorably (they are costly). The evaluations of costs and rewards associated with individual group members represent idiosyncratic judgments. That is to say, individuals can form impressions of each group member uniquely based on their own contributions and those of the other member regardless of group norms. We argue that the minimax principle predicts personal 
attraction because it reflects judgments of the individual rather than the group as a whole.

\section{Group member contributions as communication}

Both equity theory and the minimax principle rely on the ability of group members to compare their own contributions to those of other group members. Two important ways group members can contribute to the group are by assisting task performance (that is, task functions) and by helping maintain the relationships within the group (maintenance functions) (for example, Bales, 1953; Benne \& Sheats, 1948). Although groups may oscillate between these functions (Bales, 1953), over time contributions in each area by an individual should be valued by other group members. Focus on task or maintenance behaviors have been used to predict cohesiveness in past research (for example, Zaccaro \& Lowe, 1988).

Although the distinction between task and maintenance behaviors is important, it should not be assumed that a behavior can only be categorized as one or the other. Rather, it is more useful to think of task and maintenance behaviors as falling across two distinct continua. In this regard, a behavior could be viewed as serving both task and maintenance functions, either a task or a maintenance function, or neither function.

An illustration of the dual nature of behaviors can be found in research on mutual enhancement (Wittenbaum, Hubbell, \& Zuckerman, 1999; see also Henningsen $\&$ Henningsen, 2004; Wittenbaum \& Bowman, 2004). Mutual enhancement addresses how the pooling and repetition of information is perceived in decision-making groups. The distinction between information that is held by multiple group members (shared information) and information held by a single group member (unshared information) is highlighted by the theory. More specifically, research on mutual enhancement illustrates how the pooling and repetition of shared information enhances the standing of group members with their colleagues.

Clearly, pooling or repeating decision relevant information can be identified as a task oriented behavior regardless of whether it is shared or unshared (for example, Hirokawa, 1980). However, research findings

Groupwork Vol. 23(1), 2013, pp.73-93. DOI: 10.1921/1701230105 
dealing with mutual enhancement indicate that discussing an item of shared information can simultaneously influence the relationships among group members (Wittenbaum et al, 1999) Information sharing on a decision-making task that promotes more favorable perceptions among the group members should be characterized as a maintenance oriented, as well as a task oriented, behavior.

The tendency to focus on communication behaviors as representing either a task or a maintenance function likely emerges from research relying on coding systems such as the Interaction Process Analysis (Bales, 1950,1970). Such approaches classify statements as either a task or maintenance behavior. However, research indicates coded characterizations of interactions often conflict with individuals' perceptions of the interactions (Cruz, Henningsen, \& Miller, 1999; Henningsen \& Henningsen, 2006).

We argue that individuals form assessments of task and maintenance contributions based on their perceptions of group communication during group interaction. More specifically, we predict that perceptions of individuals' contributions to task and / or maintenance functions during group interactions will form the basis by which judgments of social and personal attraction are formed. We operationalize perceptions of task and maintenance contributions as the percentage of group time individuals think other group members contributed to task and maintenance functions.

As noted above, when individuals make assessments about their attraction to the group itself (that is, social attraction) equity forces should dictate their responses based on the logic we have presented. Generally, according to equity theory, it would be expected that individuals would favor groups in which the average contributions of other group members to task and maintenance functions are similar to the individuals' own contributions. Because social attraction focuses on the development of, and comparison to, a group prototype, a comparison to the average group member is the logical focus. If an individual's perceived contributions to the group exceed those of the prototypical member, the individual would perceive themselves to be under-benefited by the group. In contrast, when the typical group member makes stronger contributions than the individual, the individual should feel over-benefited. Thus, we would anticipate the greatest social attraction when individuals perceive little difference 
between their own and other group members' contributions to task and to maintenance functions. This is reflected in Hypothesis One

\section{Hypothesis One}

A quadratic relationship will exist between perceived differences in member contributions to task and maintenance functions and attraction to the group (social attraction) so that smaller differences in perceived contributions will produce greater social attraction.

When individuals assess their liking for other individuals within a group (personal attraction) it is anticipated that they will seek to maximize rewards and minimize costs. When the perceived contributions of another group member to the group exceed those of an individual, the individual should be more attracted to that member because the individual's rewards that generate from having that member in the group are greater than the corresponding costs contributed to the group. In contrast, when another group member makes fewer perceived contributions to a group than the individual, the individual should like that member less because that person is generating too few benefits relative to the cost of group membership. Hypothesis Two addresses these predictions:

\section{Hypothesis Two}

A linear relationship will exist between perceived differences in member contributions and attraction to group members (personal attraction) so that personal attraction will be greatest when individuals perceive their own contributions are smaller than those of others and least when individuals perceive others' contributions are smaller than their own.

\section{General attraction}

Because personal attraction is based on idiosyncratic bases of attraction, it would be expected that personal attraction would increase based on factors that generally increase liking whereas social attraction would not. In personal relationships, one such variable is physical attractiveness (for example, Walster, Aronson, Abrahams, \& Rottmann, 1966; White, 
1980). Because physical attractiveness should generally be perceived as a rewarding characteristic of group members, but not necessarily a factor that group members consider pertinent to the group prototype in task performing groups, it is predicted that personal attraction would increase with greater perceived physical attractiveness of a group member.

In addition to illustrating how personal characteristics more strongly influence personal rather than social attraction, we also consider physical attractiveness as a way to gauge the relative strength of communication compared to non-communication forces in the development of attraction. Although communication may influence the perceived physical attractiveness of an individual, we think physical attractiveness is primarily a non-communication variable based on an individual's physical traits. We contrast this with communication as represented in this study by perceptions of task and maintenance contributions. This contrast allows us to better judge the overall effect communication has on attraction in groups. No effects are predicted for physical attractiveness on social attraction.

\section{Hypothesis Three}

Increases in the physical attractiveness of group members will be associated with increases in personal attraction to the group members.

\section{Method}

\section{Participants}

Participants were students in an introductory communication course at a large, North American university. Overall, 182 participants participated in 35 groups of four to six members.

\section{Procedures}

Participants were randomly assigned to groups as part of an introductory communication course. Group membership lasted for an entire semester. Each group was responsible for weekly graded homework assignments performed together in class as well as a graded group project and 
presentation. Although it was possible that group members could work on aspects of the group project without all members being present, the nature of the group presentation required that group members spend considerable effort working together as a team. After all graded work was completed, but before participants knew their final grades for the group projects, participants filled out a questionnaire measure assessing all group members, themselves included, on task and maintenance behaviors during the semester. In addition, they assessed the physical attractiveness of each group member. Participants also assessed personal (attraction to individual members) and social attraction (attraction to the group).

\section{Measures}

\section{Task behaviors}

Each participant evaluated all group members, including themselves, for how much of the group time the member spent focused on task performance. Specifically, group members were asked:

What percentage of the time your group spent together did this member spend on task oriented behaviors (i.e., focusing specifically on the group's performance and the task at hand)?'

Individual scores could range from 0 (no time spent focused on group tasks) to 100 (all time spent focused on group tasks). Individuals rated the task behaviors of their fellow group members, $M=75.61$, and $S D$ $=20.57$, and their own task behaviors, $M=78.51$ and $S D=17.39$. $\mathrm{A}$ difference score, potentially ranging from -100 to 100 , was calculated for task behaviors by subtracting perceptions of other group members' scores from the individual's assessment of their own task behaviors, $M$ $=3.01, S D=20.54$. A squared difference score was also calculated in order to explore the quadratic predictions associated with equity theory, $M=430.24, S D=1113.30$.

\section{Maintenance behaviors}

Each participant evaluated all group members, including themselves, for how much of the group time the member spent focused on socioemotional concerns in the group. Specifically, group members were asked: 
What percentage of the time your group spent together did this member spend on socio-emotional concerns of the group (i.e., focusing on maintaining social relations among group members)?

Individual scores could range from 0 (no time spent focused on group relations) to 100 (all time spent focused on group relations). It should be noted, group members were not constrained to consider time as spent on either task or maintenance functions. Thus, the sum of the task and maintenance behaviors could exceed 100 for each individual. Individuals rated other group members' maintenance behaviors, $M=$ 40.23 , and $S D=30.26$ and their own maintenance behaviors, $M=41.32$ and $S D=30.95$, over the course of the semester. A difference score, potentially ranging from -100 to 100, was calculated for maintenance behaviors by subtracting perceptions of other group members' scores from the individual's assessment of their own maintenance behaviors, $M=1.04, S D=22.73$. A squared difference score was also calculated, $M=516.91, S D=1252.45$.

\section{Reliability of behavior perceptions}

Both perceptions of task behaviors and perceptions of maintenance behaviors utilized one item measures precluding the use of a measure of inter-item reliability. The reliability of these measures was assessed, alternatively, by calculating a Cronbach's ( $\boldsymbol{\alpha}$ ) within each group for the consistency of member evaluations across group members. The average $\alpha$ across all groups was deemed acceptable, $\alpha=.79$, range $=.50$ to .89 . Only two group's generated $\alpha$ 's less than $\alpha=.67$ and only one with $\alpha$ $<.62$. Overall, the reliability of these measures was deemed acceptable.

We believe we capture perceptions of communication behaviors by focusing on estimates of the amount of time individuals spent during group interactions on task and maintenance oriented behaviors. Although individuals could have made contributions to the group outside of group meetings that are not reflected in our measures, those contributions would not reflect group communication and therefore do not directly relate to the current studies. The extent such contributions strongly influence attraction in groups would tend to obscure the effects of perceptions of communication as measured in this study.

\section{Attractiveness}


Each participant assessed the perceived attractiveness of each other group member. Two semantic differential items (physically attractive - physically unattractive; good-looking - not good-looking), $r=.94, p$ $<.05$, were averaged to produce an attractiveness score for each group member, $M=3.98, S D=1.33$. Scores ranged from 1 to 7 . Higher scores indicated greater physical attractiveness.

\section{Personal attraction}

Personal attraction was designed to measure liking of individual group members. Six measures anchored at one and seven were used to assess how much each participant liked each of their fellow group members, $\alpha=.92, \mathrm{M}=4.67, \mathrm{SD}=1.38$ (for example How much do you like this member? 1 = Very little, 7 = Very much). Scores were coded so that higher scores indicated more liking.

\section{Social attraction}

Social attraction was measured as the desire to work with the group again in the future. Four Likert type items scaled from one to seven were utilized to assess social attraction (for example, I would like to continue to work with this group in the future). Overall, the reliability of the social attraction measure was adequate, $\alpha=.88, M=5.77, S D=$ 1.44. Higher scores indicate greater social attraction.

Although they represent different constructs, we would expect social attraction and personal attraction to be related to one another. It is important to identify the level of association between social and personal attraction. As each measure employs a unique unit of analysis, social attraction acting as an evaluation of the group and personal attraction as an evaluation of the group members, the average personal attractiveness for each participant was calculated as a group level measure of personal attractiveness. Because individuals are nested in groups, a semi-partial correlation, $\mathrm{sr}=.39$, was calculated for the effect of personal attraction on social attraction after removing the group effects by including a series of $\mathrm{N}$ (the number of groups) -1 dummy codes in a stepwise regression analysis (Cohen \& Cohen, 1983). 


\section{Results}

\section{Social Attraction}

The average difference between the task and maintenance behaviors of the individual and each of the other group members was calculated to assess minimax forces. As noted above, social attraction represents a comparison to the group prototype justifying a comparison to the group as a whole rather than each individual member. A negative relationship between perceived differences in contributions and social attraction indicates a group is preferred when the participant perceives the other group members, on average, contributed more to the group than the participant consistent with the minimax principle. A negative relationship between the average squared difference score and social attraction would support the predictions based on equity theory that attraction increases as differences from the group prototype decrease. The average difference scores and the average square of the difference scores were regressed onto social attraction.

In addition, the average attractiveness ratings of fellow group members and a series of $n-1$ dummy codes where $n$ represents the number of groups were also entered in the regression equation. Dummy codes were used to account for the effects of different participants belonging to the same groups (see Cohen \& Cohen, 1983 on nested designs).

A stepwise regression was performed. The dummy coded variables were entered on the first step and the predictor variables were entered on the second. The first step produced a significant multiple regression coefficient, $R=.62, p<.05$. The second step produced a significant change in $R^{2}, R^{2}$ change $=.12, \mathrm{p}>.05$. Overall, the multiple regression coefficient for the entire analysis was significant, $R=.71, p<.05$. In addition, a significant relationship emerged between the squared difference in task behavior and social attraction, $\beta=-.37, p<.05$. No other predictor variables produced a significant relationship with the criterion variable (task difference, $\beta=.05, p>.05$; socio-emotional difference, $\beta=-.07, p>.05$; squared socio-emotional difference, $\beta=$ $.02, p>.05$; attractiveness, $\beta=.14, p>.05$ ). Hypothesis 1 is partially supported. 


\section{Personal attraction}

Every participant rated how much personal attraction they felt for each of their fellow group members. Thus, multiple scores for each participant are included in the regression analysis. Personal attraction was regressed onto the perceived differences in task and maintenance behaviors for the participant and each other group member to assess whether the minimax principle predicted personal attraction. A negative relationship between the perceived difference and personal attraction indicates support for the minimax principle. Equity forces were simultaneously examined by including the squared differences in task and maintenance behaviors between the participant and each other group member in the regression equation. A negative relationship between personal attraction and the squared differences indicates personal attraction increased when group members contributed about the same amount to the group as the participant consistent with equity theory. Additionally, participant ratings of group member attractiveness were also included in the regression.

Because each participant's ratings of each other group member are considered unique units of analysis, a series of $\mathrm{N}-1$ dummy codes, where $N$ equals the total number of participants, was included in the regression to account for individual effects (Cohen \& Cohen, 1983). Finally, because data was collected from members of groups, a series of $n-1$ dummy codes, where $n$ equals the number of groups, was included in the regression equation to account for group effects.

A stepwise regression was performed in which the dummy coded variables were entered in the first step and the predictor variables were entered in the second step. The first step of the regression was significant, $R=.65, p<.05$. Furthermore, the second step in the regression produced a significant effect, $R^{2}$ change $=.25, p<.05$, and the overall multiple regression coefficient was significant, $R=.82, p<$ .05. Significant effects emerged for difference in task behaviors, $\beta=-.32$, $p<.05$, and for difference in maintenance behaviors, $\beta=-.23, p<.05$ supporting Hypothesis 2. In addition, a significant effect was produced for physical attractiveness, $\beta=.42, p<.05$, supporting Hypothesis 3 . The squared difference terms did not produce significant results (task, $\beta=-.08, p>.05$; maintenance, $\beta=-.06, p>.05$ ). 


\section{Discussion}

It was hypothesized that social attraction would be predicted by equity forces but that personal attraction would best be explained by minimax forces. Based on these predictions, individuals' perceptions of their own and their fellow group members' task and maintenance behaviors as well as the perceived physical attractiveness of group members were examined in relation to social and personal attraction. Generally, support for each hypothesis was found.

In Hypothesis 1, it was posited that social attraction would be predicted by equity forces. More specifically, it was predicted that the squared difference between individuals' perceptions of their own and the average ranking of their fellow group members' task and maintenance behaviors would be negatively related to social attraction. The squared difference term indicates how much individuals violate equity without regard to whether the violation produces over-benefittedness or underbenefittedness. This hypothesis was partially supported.

Perceptions of task, but not maintenance, behaviors produced the hypothesized equity effects. Individuals' social attraction to the group as a whole was greatest when the average perceived differences in the task contributions of the individual and the other group members were smallest. This fits well with the idea that social attraction is based on group members identifying with each other. Social attraction is based on how well individuals perceive they embody the group prototype (for example, Hogg \& Hains, 1998). Equity forces reflect the extent to which we perceive that we exceed, undercut, or match the group in terms of contributions. Group members who perceive their contributions are equitable should feel that they are a better match to the group prototype.

In contrast, as other group members' contribution to the group, relative to that of the participant, increased participants liking of that group member increased as well. Generally, participants liked those members best who exceeded their own contributions to the task and maintenance functions of the group without regard to equity. These findings support Hypothesis 2.

Personal attraction scores were also significantly influenced by the perceived attractiveness of other group members. Consistent with the idea that personal attraction is idiosyncratic (for example, Hogg $\&$ Hains, 1998), people reported more personal attraction for more 
attractive group members. This finding supports Hypothesis 3.

An illustrative example may be useful in interpreting the results of our study. Consider a player on a basketball team. Based on market forces, we would predict that player would most like the best players on the team. However, when considering the team as a whole, that same player will be most attracted to a team where they are neither much better nor much worse than their teammates.

\section{Physical attractiveness}

As anticipated, physical attractiveness was a significant predictor of personal but not social attraction. This is consistent with the conceptualizations of these phenomena (for example, Hogg et al., 2004). Consideration of the contribution of physical attractiveness to social and personal attraction provides a contrast for our assessment of the role played by perceptions of communication in the formation of these judgments. Interestingly, the $\beta$ 's for personal attraction indicate physical attractiveness has an effect as strong or stronger than communication as measured by perceived contributions to task and maintenance functions during group interactions. This may indicate the relative contribution of communication to attraction compared to assessment of individual traits depends on whether equity or market forces are the strongest predictors of attraction.

\section{Relational framing theory}

It is interesting that task behavior perceptions dominated social attraction whereas perceptions of both maintenance and task behaviors influenced personal attraction. Insight into these findings may be uncovered using relational framing theory (Dillard, Solomon, \& Palmer, 1999; Dillard, Solomon, \& Samp, 1996). Relational framing theory posits that two frames are evoked in any communication setting: Dominance - submissiveness and affiliation - disaffiliation. Dillard and his colleagues have argued that dominance or affiliation frames are used to form judgments about communication interactions and that these frames will be differentially salient in different contexts.

Past research has applied relational framing theory to group contexts (Henningsen, Henningsen, Cruz, \& Morrill, 2003). The findings of 
Henningsen et al (2003) link salience judgments of affiliation and dominance to a focus on task or maintenance. When groups are instructed to primarily focus on the task, the affiliation frame tends to be subordinate to the dominance frame. However, when groups' focus is centered on the relations among the members the affiliation frame become prominent. Research has further indicated that need for dominance is associated with task roles but not for maintenance roles suggesting that dominance may be the primary frame for task roles (Mudrack \& Farrell, 1994).

Our results indicate that task perceptions most strongly influenced perceptions of social attraction. This can be interpreted as indicating the dominance frame is most salient when considering social attraction. However, although perceptions of maintenance behaviors did significantly influence personal attraction, perceptions of task behavior did as well. This implies dominance and affiliation themes can be activated simultaneously.

\section{Further theoretical implications}

The relative importance of equity and market forces across social and personal attraction may have important implications for how equity theory (for example, Walster et al, 1973) and theories grounded in market forces (for example, Thibault \& Kelly, 1959) may be reconciled. Rather than adopting one or the other theoretical framework, the current research indicates scholars would benefit by determining the contexts in which equity or market forces would be most salient. One such factor identified in this study is the extent to which normative forces may be relevant. We argue that attraction to the group (social attraction) is more subject to normative forces and thus more prone to equity rather than market forces. In contrast, attraction to individual group members (personal attraction) invokes less normative force and therefore adheres more to market forces.

\section{Limitations}

The current research presents an advance in understanding how individual behavior in group interactions influences forces related to cohesiveness, yet some caution is warranted in interpreting the results. 
The measures used to evaluate communication behaviors in this study utilized perceptions of behavior rather than coding actual behaviors. Although it can be argued how behaviors are perceived may be as important as the nature of the acts themselves, research that examines both measures of behavior and perceptions of behaviors would provide a fuller picture of the role of communication in the formation of social and personal attraction in groups.

In addition, the measures of perceptions of communication employed in this study forced group members to focus only on time spent with the group in group interaction. Clearly group members can make contributions to the group outside of the context of group interactions. Future research may benefit by exploring how perceptions are influenced by the contributions members make beyond the context of group interaction.

It is always somewhat problematic to draw conclusions based solely on student groups. However, student groups can be very effectively utilized to examine group processes (for example, Kamau, 2010). Because student groups complete a specific group task in a relatively limited amount of time, they offer a valuable opportunity to study groups dealing with tasks that have real world consequences.

\section{Directions for future research}

The study of groups and communication would benefit by the development and application of theories to better understand group processes (Poole, 1990). Although the current study applies equity theory and the minimax principle to concepts related to group cohesiveness, further insights may be provided by exploring relational framing theory. Understanding when dominance or affiliation frames become stronger could provide greater understanding of the role of task and maintenance behaviors in the formation of attraction in groups.

The current study also presents a possible reconciliation between theoretical frameworks focusing on equity and market forces. Our results indicate both may adequately explain attraction in groups depending on the type of attraction that is being focused on. Further exploration of how market and equity forces may work simultaneously could advance theoretical understanding.

The present study benefited from being able to employ work groups

Groupwork Vol. 23(1), 2013, pp.73-93. DOI: 10.1921/1701230105 
who interacted with each other over a fifteen week period and employed group members for whom group success was meaningful and relevant. However, it is worth noting that generalizations based on student groups are always somewhat risky. Future researchers would be well served to examine how equity and minimax forces influence personal and social attraction in different populations and contexts.

In addition, we intentionally assessed perceptions of task and socioemotional communication as well as social and personal attraction before the participants received feedback about their performance. Clearly, feedback about the quality of group performance can influence satisfaction with the group (for example, Scudder, Herschel, \& Crossland, 1994). Performance feedback has also been shown to bias perceptions of group processes (Henningsen, Henningsen, Eden, \& Cruz, 2006). Future research that explores social and personal attraction both before and after groups receive feedback about the quality of their performance could be enlightening.

\section{Conclusion}

Group research benefits by examining groups engaged in tasks over time with meaningful consequences for the group members. Overall, the current study offers insights into how perceptions of communication in groups across a semester influence the formation of social and personal attraction when the group members are striving to attain a good grade. Theoretical insights are advanced concerning theories rooted in equity and market forces.

\section{References}

Bales, R. F. (1950) Interaction process analysis: A method for the study of small groups. Reading MA: Addison-Wesley

Bales, R. F. (1953) The equilibrium problem in small groups. in T. Parsons, R. F. Bales \& E. A. Shils (Eds.) Working papers in the theory of action Glencoe, IL: Free Press (pp. 111-161)

Bales, R. F. (1970) Personality and interpersonal behavior. New York: Holt, Rinehart $\&$ Winston 
Benne, K. D. \& Sheats, P. (1948) Functional roles of group members. Journal of Social Issues, 4, 41-49

Burnette, J. L., Pollack, J. M. \& Forsyth, D. R. (2011) Leadership in extreme contexts: A Groupthink analysis of the May 1996 Mount Everest disaster. Journal of Leadership Studies, 4, 29-40

Cohen, J. \& Cohen, P. (1983) Applied multiple regression / correlation analysis for the behavioral sciences, $2^{\text {nd }} \mathrm{ed}$. Hillsdale, NJ: Lawrence Erlbaum

Cruz, M.G., Henningsen, D.D. \& Miller, M.L. (1999) The presence of norms in the absence of groups? The impact of normative influence under hidden profile conditions. Human Communication Research, 26, 1, 104-124

Deutsch, M. \& Gerard, H. B. (1955) A study of normative and informational social influences upon social judgment. Journal of Abnormal and Social Psychology, 51, 629-636

Dillard, J. P., Solomon, D. H. \& Palmer, M. T. (1999) Structuring the concept of relational communication. Communication Monographs, 66, 49-65

Dillard, J. P., Solomon, D. H. \& Samp, J. A. (1996) Framing social reality: The relevance of relational judgments. Communication Research, 23, 703-723

Forsyth, D. R. (2006) Group Dynamics. 4 $^{\text {th }}$ edition. Belmont, CA: ThompsonWadsworth

Henningsen, D. D. \& Henningsen, M. L. M. (2004) Examining how individual difference variables influence information sharing in decision-making groups. Human Communication Research, 30, 540-555

Henningsen, D. D., Henningsen, M. L. M., Eden, J. \& Cruz, M. G. (2006) Examining the symptoms of groupthink and retrospective sensemaking. Small Group Research, 37, 36-64

Henningsen, M. L. M. \& Henningsen, D. D. (2006) Perceiving influence in group discussion: Perceptions and statements of normative and informational influence. Paper presented to the Interdisciplinary Network for Group Research, Pittsburg, PA, July, 2006

Henningsen, M. L. M., Henningsen, D. D., Cruz, M. G. \& Morrill, J. (2003) Normative influence in decision-making groups: Evaluating information in discussion. Communication Monographs, 70, 175-196

Hirokawa, R. Y. (1980) A comparative analysis of communication patterns within effective and ineffective decision-making groups. Communication Monographs, 47, 312-321

Hogg, M. A., Abrams, D., Otten, S. \& Hinkle, S. (2004) The social identity perspective: Intergroup relations, self-conception, and small groups. Small Group Research, 35, 246-276

Groupwork Vol. 23(1), 2013, pp.73-93. DOI: 10.1921/1701230105 
Hogg, M. A. \& Hains, S. C. (1998) Friendship and group identification: A new look at the role of cohesiveness and groupthink. European Journal of Social Psychology, 28, 323-341

Hogg, M. A. \& Hardie, E. A. (1991) Social attraction, personal attraction, and self-categorization: A field study. Personality and Social Psychology Bulletin, 17, 175-180

Janis, I. (1972) Victims of groupthink. Boston: Houghton Mifflin

Janis. I. L. (1983) Groupthink (2nd ed.). Boston: Houghton

Janis, I. \& Mann, L. (1977) Decision making. New York: Free Press.

Kamau, C. (2010) In group attraction, coordination and individualism as predictors of student task performance. Group Work: An Interdisciplinary Journal of Working with Groups, 20, 34-62

Kaplan, M. F. (1989) Task, situational, and personal determinants of influence processes in group decision making. in E. J. Lawler (Ed.) Advances in group processes (Vol. 6, Greenwich, CT: JAI. (pp. 87-105)

Keyton, J. \& Springston, J. (1990) Redefining cohesiveness in groups. Small Group Research, 21, 234-254

Mach, M., Dolan, S. \& Tzafrir, S. (2010) The differential effect of team members' trust, on team performance: The mediation role of team cohesion. Journal of Occupational and Organizational Psychology, 83, 771-794

Moreland, R. L. \& Levine, J. M. (1982) Socialization in small groups: Temporal changes in individual-group relations. in L. Berkowitz (Ed.) Advances in experimental social psychology, vol. 15. New York: Academic Press, (pp. 137192)

Mudrack, P. E. \& Farrell, G. M. (1994) The need for dominance scale of the manifest needs questionnaire and role behavior in groups. Applied Psychology: An International Review, 43, 399-413

Mullen, B. \& Copper, C. (1994) The relation between group cohesiveness and performance: An integration. Psychological Bulletin, 115, 210-227

Poole, M. S. (1990) Do We Have Any Theories of Group Communication? Communication Studies, 41, 237-247

Scudder, J. N., Herschel, R. T. \& Crossland, M. D. (1994) Test of a model linking cognitive motivation, assessment of alternatives, decision quality, and group process satisfaction. Small Group Research, 25, 57-82

Shin, Y. \& Song, K. (2011) Role of face-to-face and computer-mediated communication time in the cohesion and performance of mixed-mode groups. Asian Journal of Social Psychology, 14, 126-139

Thibaut, J. \& Kelley, H. H. (1959) The social psychology of groups. New York: Wiley 
Walster, E., Aronson, V., Abrahams, D. \& Rottman, I. (1966) Importance of physical attractiveness in dating behavior. Journal of Personality and Social Psychology, 4, 508-516

Walster, E., Berscheid, E. \& Walster, G.W. (1973) New directions in equity research. Journal of Personality and Social Psychology, 25, 151-176

White, G. (1980) Physical attractiveness and courtship progress. Journal of Personality and Social Psychology, 39, 660-668

Wittenbaum, G. M. \& Bowman, J. M. (2004) A social validation explanation for mutual enhancement. Journal of Experimental Social Psychology, 40, 169-184

Wittenbaum, G. M., Hubbell, A. P. \& Zuckerman, C. (1999) Mutual enhancement: Toward an understanding of the collective preference for shared information. Journal of Personality and Social Psychology, 77, 967-978

Zaccaro, S. J. \& Lowe, C. A. (1988) Cohesiveness and performance on an additive task: Evidence for multidimensionality. Journal of Social Psychology, 128, 547-558 